\title{
The Impact of Information on Willingness to Pay and Quantity Choices for Meat and Meat Substitute
}

\author{
${ }^{1}$ Economia Agroalimentare, Università Cattolica del Sacro Cuore, Piacenza, Italy \\ ${ }^{2}$ UMR Économie Publique, INRA, Université Paris-Saclay, F-78850 Crignon, France, E-mail: marette@agroparistech.fr
}

\begin{abstract}
:
We evaluate the impact of different types of information on participants' willingness-to-pay (WTP) and quantity choices for both beef and soy burger meat. To this end, we conducted a lab experiment to elicit WTP with multiple-price lists and chosen quantities of two products in a basket. Participants were provided with explanatory messages regarding the impact of beef and soy on health and environment before successive rounds of WTP determinations and quantity choices. Results show a weak impact of successive rounds of messages on WTP for both beef and soy, while leading to higher relative variations for chosen quantities. These relative changes in both WTP and quantities are then combined for computing the value of information. Results show a relatively low value of information compared to the expenditure for beef. In the last section of the paper we evaluate the effect of the introduction of a beef burger labeled "Fed without GMO" on WTP and quantity choices. Results underline a weak impact of "Fed without GMO" label on changing participants' preferences.
\end{abstract}

Keywords: experimental economics, meat, information, consumers' preferences

JEL classification: $\mathrm{C} 9$, D8, I1

DOI: $10.1515 /$ jafio-2017-0028

\section{Introduction}

Breeding beef cattle implies an intensive land use and leads to high levels of greenhouse gas emissions (Westhoek et al. 2014). Moreover, an excess of meat consumption is linked to diets characterized by relatively high intakes of fats, saturated fatty acids and salt, and by relatively low intakes of dietary fiber, vitamins and micronutrients. Several studies have found a positive relationship between meat consumption and both cancer and cardiovascular disease mortality (Lock et al. 2010; Wein 2012).

Consumers' intentions to reduce meat consumption are often thwarted by entrenched habits, favoring meat consumption in regular diets (Graça, Calheiros, and Oliveira 2015; Grunert 1997). Many developed countries are characterized by overconsumption of animal-based proteins, while health and environmental benefits coming from plant-based proteins are overlooked by many consumers. Given the persistence in eating habits, the changes towards more sustainable diets, aiming at reducing meat consumption, are difficult to achieve. Besides market-based policies, such as meat taxation, another solution consists in implementing information campaigns regarding the long-term consequences of consumption habits on environment and health.

This paper aims at evaluating the impact of explanatory messages about health and environment on consumers' willingness-to-pay (WTP) for a meat product and a plant-based substitute. Specifically, we conducted a lab experiment to analyse consumers' choices between beef and soy burgers. We selected these two products for several reasons. First of all, given the two products have strong similarities in appearance, they are potentially close substitutes. Another reason is that beef (respectively soybean) is one of the products with the lowest (respectively highest) protein efficiency per greenhouse gas emissions (González, Frostell, and Carlsson-Kanyama 2011). Last, soy burgers were introduced on the market before and after the time of the experiment.

The lab experiment was run with 127 participants in November 2016 in Milan, Italy. WTP and choices between these different products were elicited providing different rounds of information. Explanatory messages about the impact of beef and soybean on health and environment were sequentially revealed to participants. The order of messages varied across sessions, each attended by different participants. The set of messages underlined the relative benefits of increasing consumption of soy meat compared to beef.

Stéphan Marette is the corresponding author.

(c)) BY-NC-ND $\odot 2019$ Castellari et al., published by degruyter.

This work is licensed under the Creative Commons Attribution-NonCommercial-NoDerivatives 4.0 License. 
Because we could not fully guarantee the freshness of products that could be given or sold to consumers at the end of the experiment, we only elicited hypothetical WTP with a multiple-price list. In other words, we did not give or sell any product at the end of the experiment. Despite the risk of hypothetical and upward biases of WTP, the lab is a practical place for eliciting well-informed, thoughtful preferences with a tight control of the revealed information. ${ }^{1}$ In other words, the main advantage of a lab experiment compared to a field experiment in a real context is the precise control of information revealed to participants, which is impossible to get in real contexts. $^{2}$

Results show a weak impact of successive rounds of messages on WTP for both beef and soy products. Indeed, between the first and the fifth round, we measure a relative decrease of WTP for beef equal to $-1.55 \%$, and a relative increase of WTP for soy equal to $+3.59 \%$. These explanatory messages lead to a significant change in chosen quantities, with an average shift of 0.764 units from beef towards soy within a basket of 5 units.

Our results show a larger relative change in chosen quantities than in WTP. From the first to the fifth round, we measure relative variations for the chosen quantity of beef and soy respectively equal to $-23.03 \%$ and $+45.55 \%$, versus relative variations of $-1.55 \%$ and $+3.59 \%$ for the WTP of beef and soy, respectively. One possible explanation for this result is that making quantity choices for a basket of products under different contexts of information is possibly more natural and more immediate than determining WTP for one unit of product, which can be seen as more artificial. Indeed, in supermarkets, consumers are directly choosing products' quantities rather than directly formulating WTP or bids as for an auction. Another explanation is linked to the fact that consumers place a greater value on soy burgers when several units are purchased, but they are unwilling to pay more for soy than for beef when only one unit is offered for determining WTP.

We further combined these relative changes in both WTP and quantities to compute the value of information, as a welfare measure of messages' impact. This value of information is relatively low, since it represents $3.49 \%$ of the initial expenditure for beef.

In the last section of the paper we evaluate the impact of the introduction of a beef burger labeled "Fed without GMO" on consumers' preferences. We found this last label has a weak impact on changing participants' preferences, both considering WTP and quantity choices.

By showing a limited impact of messages on participants' preferences, this paper supports some previous results underlining a relatively strong attachment towards meat that hinders a shift towards a more plant-based diet (Graça, Calheiros, and Oliveira 2015; Hoek et al. 2004). However, our present paper evaluating WTP differs from previous non-economic studies focusing on meat replacement without any monetary values. de Boer, Hoogland, and Boersema (2007), Krystallis et al. (2012), and Zur and Klöckner (2014) focused on attitudes and intentions to reduce meat consumption, but they overlooked the revelation of diverse messages under different orders. Conversely, our protocol precisely controls the diversity of messages and the order of these messages.

Additionally, while previous studies support significant relationships between socio-demographic variables and consumers' attitudes to reduce meat purchases (Krystallis et al. 2012), our paper does not find any significant relationship between WTP for beef and soy-based products and education level or socio-economic status.

Moreover, combining both WTP and choice quantity, this work also contributes to the literature on food lab experiments (see Lusk and Shogren 2007, for a complete overview). While previous papers focus either on the mechanisms for eliciting the WTP for one unit (Alphonce and Alfnes 2017), or on choosing different quantities of substitute goods (Masters and Sanogo 2002), the present work simultaneously measures for the two products (i. e., beef and soy burgers) the unit WTP and a basket with chosen quantity of the two. We found the impact of information is stronger when we refer to relative changes in quantities rather than relative changes in WTP. Such difference was overlooked by previous papers (Lusk and Shogren 2007). Finally, differing from previous approaches (Lusk and Marette 2010), we implemented a new methodology to measure the value of information combining both changes in WTP and quantities.

The paper is organized as follows. In Sections 2 and 3 we respectively describe the protocol and present the results of the experiment, conclusions follow in Section 4.

\section{The Experiment}

\subsection{The Sample}

The experiment was conducted in eight sessions during November 2016, in Milan (Italy). Using a simplified quota method, we randomly selected a sample of 127 participants. The ex ante criteria for the quota were the following: (a) Sex: 50\% female and 50\% male; (b) Age: 30\% of participants are younger than 31 years old; $40 \%$ are between 31 and 60 years old; 30\% are older than 60 .

Participants were recruited by phone and were informed that the experiment would focus on meat consumption and it would last about one hour. During this phone interview, as additional selection criteria, peo- 
ple were asked if they consume beef. Only participants eating beef and beef burger meat (ground beef), even occasionally, were selected. Each participant was compensated with a purchasing coupon of $€ 15$ value.

Each experimental session lasted on average 50 minutes and included between 8 and 16 participants. From the initial 127 participants, observations related to 8 participants were excluded because of incomplete replies. Therefore, the rest of this paper only takes into account a sample of 119 participants. This sample size is usual for a lab experiment lasting one hour with the effective presence of participants (Lusk and Shogren 2007; Roosen and Marette 2011).

Regarding the representativeness of this sample, we compare demographics characteristics of the inhabitants of Milan and Lombardy region with the experiment participants (Table 1). We notice very minor differences between the age of participants and the age of inhabitants of Lombardy, while data referred to education level shows some sizeable differences between the two. One possible explanation comes from the fact that the census data belongs to the whole Lombardy region, while our sample was selected only in Milan, where, on average, the population is supposed to have higher education levels than the regional average.

Table 1: Socio-economic characteristics of participants and inhabitants from Lombardy.

\begin{tabular}{|c|c|c|}
\hline & Experiment & Lombardy \\
\hline Number of participants & 119 & \\
\hline \multicolumn{3}{|l|}{ Participants' Gender (\%) } \\
\hline Male & 53.3 & $47.8^{\mathrm{b}}$ \\
\hline Female & 46.7 & $52.2^{\mathrm{b}}$ \\
\hline \multicolumn{3}{|l|}{ Participants' Age (\%) } \\
\hline$<30$ & 27.9 & $26.7^{\mathrm{b}}$ \\
\hline [30-39] & 14.4 & $13.8^{\mathrm{b}}$ \\
\hline [40-49] & 11.9 & $16.8^{\mathrm{b}}$ \\
\hline [50-59] & 13.7 & $13.9^{\mathrm{b}}$ \\
\hline$\geq 60$ & 32.2 & $28.7^{\mathrm{b}}$ \\
\hline \multicolumn{3}{|l|}{ Participants' Education (\%) } \\
\hline No High School Diploma a & 8.5 & $57.7^{\mathrm{c}}$ \\
\hline Diploma of $2-3$ or $4-5$ years & 71.2 & $30.7^{c}$ \\
\hline More than 2 years after Diploma & 20.3 & $11.6^{\mathrm{c}}$ \\
\hline
\end{tabular}

Notes: a People in this group have no high school diploma.

b Data 2016: http://www.tuttitalia.it/lombardia/18-milano/statistiche/popolazione-eta-sesso-stato-civile-2016/

${ }^{c}$ Census 2011, Lombardia Region, source: www.istat.it

\subsection{The Products}

Since we could not guarantee the freshness of the products from the lab to the participants' home, we chose not to sell the physical product at the end of the experiment, but to elicit hypothetical WTP. During the experiment products were shown on pictures, and participants were asked to indicate choices as if they would make them in a supermarket.

As shown in Figure 1, the two products presented to participants are the following: (1) a $200 \mathrm{~g}$ vacuum packed fresh ground beef with two steaks and no brand indication, since ground beef is a widespread product, sold under different brands including supermarket brands; (2) a pack of Sojasun soy burger ( $200 \mathrm{~g})$ offering two patties.

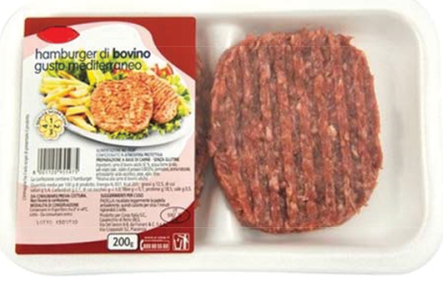

Beef burger meat

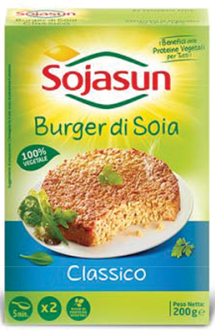

Soy burger meat

Figure 1: The pictures of products shown above the multiple-price lists. 
We selected this soy-based product, because, before the experiment, several supermarkets' visits identified Sojasun as the vegetarian brand most systematically and prominently offered on the various shelves. At the time of the experiment, this soy-based product was made with soybeans produced in Italy without Genetically Modified Organisms (GMO). One steak contained $63.6 \%$ of soy ingredients and the rest was made with various vegetables. We explicitly mentioned this well-established brand Sojasun for giving credibility to this relatively unfamiliar product, since, at the end of the first round, $50.9 \%$ of participants declared that they had never eaten vegetarian or soy meat before coming to this experimental session.

\subsection{Timeline of the Experiment}

At the beginning of the experiment, some initial explanations were read, and participants signed a consent form. We assigned a number to each participant to preserve the anonymity of the material collected and we communicated it before starting the experiment. We carefully explained that no product would be sold or given at the end of the experiment. We asked participants to indicate choices as if they were in a supermarket. We insisted on the absence of "good" or "bad" replies, but rather on the possibility to freely indicate choices reflecting their preferences.

Round \#1 was conducted without any message on health or environment. First, for the beef, we provide some generic details of the product (such as the weight). Explanations were also given about the multiple-price list (details about the mechanism will be given below). At this point participants filled out the price list for beef only. Then, we introduced the Sojasun product with some generic details, and participants filled out a price list for beef and a price list for soy, leading to both WTPs of round \#1. After, we asked participants to compose a basket of five units by choosing a combination of two available products: beef and soy burgers (details about the mechanism will be given below).

The subsequent rounds, \#2-\#6, were organized as follows. At first, the organizer distributed to participants a paper sheet containing one of the four messages and read it loud for everyone. Each participant successively filled in one multiple-price list for beef, and another for soy. In the next step each participant indicated the quantity choices of the two products selecting a basket with a total of 5 units. Before leaving the session, after round \#6, each participant filled in an exit questionnaire and received the $€ 15$ indemnity.

\subsection{The Messages about Products}

A first round of WTP elicitation was implemented without any message. For this first round, explanations about mechanisms were given (as explained below), with only a few indications describing each product. During rounds \#2-\#5, before WTP elicitations participants were provided with different types of messages about products. All four messages were written after studying articles coming from the nutrition, agronomic and environmental fields, and they were relatively short, since previous works underline that a concise and brief communication is more efficient in delivering information (Wansink, Sonka, and Hasler 2004).

We restricted our attention to messages focusing both on health and environment, which are important dimensions of sustainability. We did not tackle questions related to animal welfare. In order to focus the attention to products, messages mentioned either the term "beef" or the term "red meat", without indicating some other types of meat. Environmental messages insisted on the relative performances of both products. Following González, Frostell, and Carlsson-Kanyama (2011), we underlined that soybeans have the highest protein delivery efficiency per energy use and per greenhouse gas emissions, while beef is one of the products with the lowest protein efficiency.

The four messages, translated from the Italian language and preceding the WTP elicitations, were the following.

\subsubsection{Message about Health and Beef}

"Excessive consumption of red meat increases the risk of colorectal cancer. Furthermore, red meat is relatively rich in saturated fats and cholesterol.

However, eating meat in reasonable quantities is good for health. Meat provides particular amino acids of very good quality, and vitamin B12 that is not present in plants.

Nutritionists recommend eating meat (and varying the types of meat), or fish, or eggs, one or two times a day, always in a lower quantity as compared to the side dish, with a maximum of $100 \mathrm{~g}-150 \mathrm{~g}$ of meat per day." 


\subsubsection{Message about Health and Soy}

"Soybean is particularly rich in proteins, fiber and minerals. Moreover, soybean contains no cholesterol. The high content in fiber and the absence of cholesterol contribute to limit the risks of cardiovascular diseases.

For adults, soy can partially replace beef.

It is advised to mix up a consumption of soybean, with cereals such as rice or wheat, for a complete supply of essential amino acids."

\subsubsection{Message about Environment and Beef}

"The breeding of beef cattle entails a relatively high level of pollution. Beef production contributes to the emission of greenhouse gases, and uses a lot of natural resources. For example, the production of $1 \mathrm{~kg}$ of beef requires 10-15 times more water than the production of $1 \mathrm{~kg}$ of soybean.

Eating a little less meat would limit pollution and would contribute to a reasonable use of resources."

\subsubsection{Message about Environment and Soy}

"The soybean crop entails a relatively low level of pollution.

Soybean crop requires the use of very few pesticides. Moreover, no additional nitrogen fertilizer is necessary for this crop. Soybean is also an excellent preceding crop because it allows for the following crops:

- A $10 \%$ yield gain on the next crop (wheat or corn);

- The saving of $20-30 \%$ of nitrogen fertilizers for the next crop (wheat or corn).

- An improvement of the soil structure.

However, soybean is little cultivated in Italy because of a lack of opportunities, a lack of cropping habits by farmers and/or the absence of organization in supply chains.

Eating soybean steaks would increase the soybean share in Italian crops."

The provision of information was precisely controlled by equally varying the order of messages across 4 different groups of participants. 2 groups started with health messages preceding environmental messages, and 2 other groups started with environmental messages preceding the health messages.

For each type of message (health and environment), the message on beef was preceding the message on soy for groups 1 and 3, and vice versa for the other groups, 2 and 4. Participants were randomly allocated to one of 4 groups before coming to a session. Table 2 presents the order of messages for the groups G1 to G4 revealed in rounds \#2-\#5 and the number of participants for each group, for a total of 119 participants with valid entries.

Table 2: Groups depending on the order of messages.

\begin{tabular}{lll}
\hline Messages & $\begin{array}{l}\text { Order of messages related to products } \\
\text { Beef/Soy }\end{array}$ & Soy/beef \\
\hline Health and Environment & Group G1 & Group G2 \\
& 30 participants & 32 participants \\
Environment and Health & Group G3 & Group G4 \\
& 29 participants & 28 participants \\
\hline
\end{tabular}

\subsubsection{Message on CMOs}

We performed a 6th round similar for all participants of all groups, G1 to G4, in which we presented a new beef product associated with the label "Fed without GMO" that is widely used in Italy. This label was posted under the picture of the beef burger. This last round was carried out through a multiple price list for this new beef burger and the soy burger, along with a basket choice of 5 units. Before eliciting WTP for this new beef burger with the label, the soy burger, and the basket of 5 units, we provided the following message:

In Italy most of the animal feed contains genetically modified ingredients (GMOs). 
Until now, it has not been shown that the use of GM feed influences animals' health and productivity.

In addition, meat, milk, eggs and other products derived from animals fed without GMO do not have different characteristics than the corresponding products produced by animals fed with conventional feed.

However, some manufacturers have voluntarily decided to strictly avoid GMOs in feeding animals to become fresh meat of cattle, pigs and poultry.

\subsection{Mechanism for Eliciting WTP}

A multiple-price list (payment card) was used for eliciting the WTP of each product. During each round, participants were asked to choose whether or not they will buy the product displayed for prices varying from $€ 2.20$ to $€ 3.80$ per unit. Prices ranges, for both products, were selected based on a supermarket surveys in the Milan area. The average observed price was equal to $€ 2.60$ for the beef burger and to $€ 2.90$ for the soy burger. The multiple price list was characterized by increments of 10 cents between successive prices, with 8 prices lower than $€ 3$ and 8 prices higher than $€ 3$.

Participants were asked to fill out 17 lines for each product, as shown in Appendix A. For each price, they had to select either "yes", "no" or "maybe" regarding their purchase intents. For each product and each round of choice $R$ with $R=\{1, \ldots, 6\}$, the WTP was determined by taking the highest price linked to a choice "yes" (with the following highest price on the paper sheet implying a reply "no" or "maybe").

When some participants selected only one type of reply linked to one column of the multiple price list, we followed the rule selected by Marette, Blanchemanche, and Roosen (2013), mainly for simplicity. If one participant only replied "no" or "maybe", the selected WTP was equal to $€ 2.10$ (an alternative configuration with a value equal to $€ 0$ was also studied). If one participant only replied "yes" to each line, the selected WTP was equal to $€ 3.90$. For respondents switching twice at low and high prices, the highest price associated to "yes" was recorded as the WTP for the analysis. ${ }^{3}$

Multiple-price lists were employed to simplify the task for consumers when evaluating independently two products in several rounds. Criticisms against multiple price lists were brought forward by Andersen et al. (2006). One drawback is the interval response eliciting interval rather than point estimates for WTP. With our experiment, the 10 cents interval guarantees a sufficient degree of precision for the elicited WTP. Another disadvantage mentioned by Andersen et al. (2006) is the framing effect with a psychological bias towards the middle of the multiple-price list for choices made by participants. They controlled for this effect by changing the boundaries of the multiple-price list. In this paper we did not control this framing effect by changing the boundaries, since we focus on the impact of information and messages revelation.

\subsection{Choice of the Basket with 5 Products}

At the end of each round, namely after information provision and after the 2 multiple-price lists filled in for each product, each participant was asked to compose a basket with 5 units of beef and/or soy, as shown in Appendix B. Participants had to choose one combination of these two products leading to a total of 5 units, by supposing that these two products were sold at the same price, although not detailed. ${ }^{4}$

\section{Results}

This section presents analysis of both WTPs and quantity choices for beef and soy. Initially, the discussion abstracts from round \#6, in which the new type of beef "Fed without GMO" has been introduced. This specific round will be only discussed at the end of this section.

Before starting the analysis, Table 3 presents some descriptive statistics regarding the relevant variables of the experiment. From round \#1 to round \#5 we can notice the mean WTP for beef decreases of 0.04 cents, while the WTP for the soy increases of 0.1 cents. Moreover, on average, the quantity of beef included in the basket falls from 3.31 to 2.55 units. These simple statistics suggest information might have a role on shrinking the quantity choices for beef.

Table 3: Descriptive Statistics related to the 119 participants. 


\begin{tabular}{llll} 
Description & Mean & $\begin{array}{l}\text { Std. } \\
\text { Dev. }\end{array}$ & Min / Max \\
\hline Round \#1 & & & $2.1 / 3.9$ \\
WTP (€) for beef & 2.79 & 0.36 & $2.1 / 3.9$ \\
WTP (€) for soy & 2.75 & 0.49 & $0 / 5$ \\
Quantity of beef in the basket & 3.31 & 1.11 & $2.1 / 3.9$ \\
Round \#5 & & & $2.1 / 3.9$ \\
WTP $(€)$ for beef & 2.75 & 0.39 & 0.47 \\
WTP (€) for soy & 2.85 & 0.47 & 1.36 \\
Quantity of beef in the basket & 2.55 & &
\end{tabular}

\subsection{The Impact of Explanatory Messages on WTP for Products}

We now turn to the presentation of the impact of information on WTP for regular beef and soy. Figure 2 shows the average WTP for the beef (plain curves) and the soybean alternative (dashed curves). On each chart, the 5 rounds of WTP elicitation are represented on the X-axis, and the WTP are represented on the Y-axis (starting at $€ 2$ ). The different charts correspond to the different groups G1, G2, G3 and G4, in which the order of explanatory messages varied, as explained in Table 2, according to the indications on the X-axis. An average variation in WTP coming from one message is represented by the difference between two successive points.

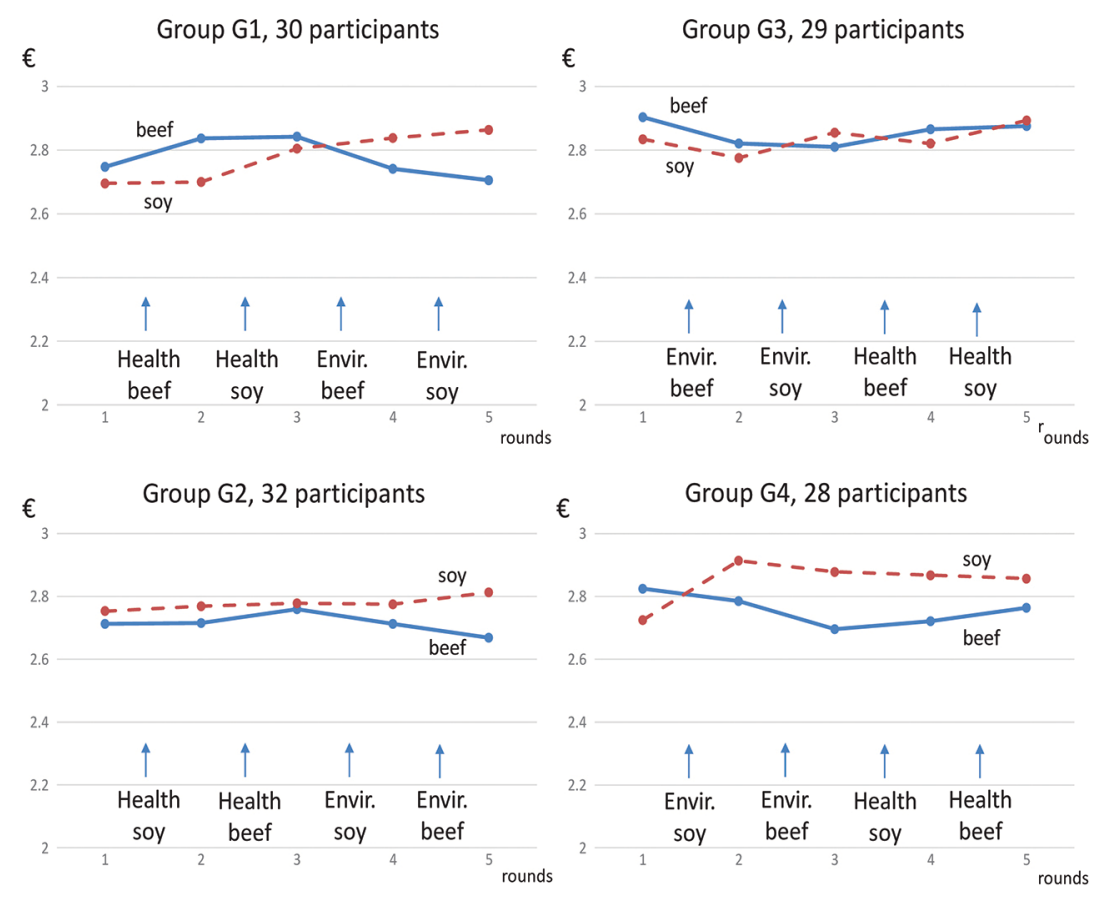

Figure 2: Average WTP (in $€$ ) for beef and soy during the first five rounds of the experiment.

Figure 2 shows that, before the revelation of explanatory messages, namely at round \#1, within each group the average WTPs for beef are very close to the average WTPs for soy. It means that the soy burger meat is seen as a relatively "close" substitute, with a possible extension of its market share if the price of beef substantially increases. Note that, at the time of the experiment, the very low market share of soy/vegetarian burger meat in Italy can be explained by: (1) the absence of soy products in many stores; (2) the average price of soy burger (around €2.90 in Italian stores) higher than the average price of fresh beef burgers (around €2.60); (3) the relatively low knowledge of consumers; (4) their strong rigidity to change dietary habits.

Figure 2 also shows that the impact of information on WTP for both products is small (recall that the Y-axis starts at $€ 2$ for facilitating the views of variations). Indeed, between the 1st round and the 5th round, and by averaging over the 119 participants, the relative decrease of WTP for beef is equal to $-1.55 \%$, and the relative increase of WTP for soy is equal to $+3.59 \%$. After the complete revelation of successive messages (round \#5), the average WTP for soy becomes a little bit higher than the average WTP for beef (except for group G3). Figure 2 underlines the limited impact of messages on the WTP variations for both products. One possible explanation of this limited impact is the strong attitude toward meat consumption that characterizes the Italian and Western diets. 
To precisely measure the impact of messages on WTP for each product, we pooled the participants' WTPs elicited in five successive rounds $R=\{1, \ldots, 5\}$, and we used a Tobit random effect estimator. The random effect imposes constraints on the structure of the variance-covariance matrix. Furthermore, WTP in levels cannot be negative and it is left-censored at $€ 2.10$ and right-censored at $€ 3.90$, which justifies the use of the random effect Tobit estimator. For a participant $i$, let $W T P_{B, R}^{i}$ denote the participant $i$ 's WTP in $€$ for beef (indicated by the notation $B$ ) as the dependent variable at round $R$ with $R=\{1, \ldots, 5\}$. Let $\mathbf{X}_{R, i}$ denote the matrix of explanatory variables indicating the rounds of information with the dummy variables, the socio-demographic and the perception variables (from the exit questionnaire). Dummy variables will be either the order of messages for one regression or the type of information for another regression. The random Tobit model for WTP for beef can be written as:

$$
W T P_{B, R}^{i}=\beta_{0}+\beta_{1} X_{R, i}+\epsilon_{R, i}
$$

with the parameters $\beta_{0}$ and $\beta_{1}$ that will be estimated, and $\epsilon_{R, i}$ being the error term. A similar expression can be written for the soy meat (replacing $B$ with S). Estimations have been performed in R using the Rchoice package (Sarrias 2016). Results of regressions are presented in Table 4.

Table 4: Estimations of regressions for pooled WTP in levels with a Tobit random effects estimator.

\begin{tabular}{|c|c|c|c|c|}
\hline \multirow{3}{*}{ Constant } & \multicolumn{2}{|l|}{ WTP for beef } & \multicolumn{2}{|l|}{ WTP for soy } \\
\hline & $2.447^{* *}$ & $2.465^{* *}$ & $2.834^{* *}$ & $2.696^{* *}$ \\
\hline & $(0.077)$ & $(0.068)$ & $(0.051)$ & $(0.046)$ \\
\hline Message received first at round $\# 2$ (dummy $=$ & -0.011 & & 0.038 & \\
\hline 1 for round $\# 2,0$ for other rounds) & $(0.024)$ & & $(0.028)$ & \\
\hline Message received second at round \#3 & -0.016 & & $0.077^{* *}$ & \\
\hline (dummy = 1 for round \#3, 0 for other rounds) & $(0.024)$ & & $(0.028)$ & \\
\hline Message received third at round \#4 (dummy & -0.025 & & $0.073^{* *}$ & \\
\hline$=1$ for round $\# 4,0$ for other rounds) & $(0.024)$ & & $(0.028)$ & \\
\hline Message received fourth at round \#5 (dummy & $-0.051^{*}$ & & $0.107^{* *}$ & \\
\hline$=1$ for round $\# 5,0$ for other rounds) & $(0.024)$ & & $(0.028)$ & \\
\hline Message about health and beef (dummy $=1$ & & 0.006 & & 0.042 \\
\hline for health \& beef, 0 otherwise) & & $(0.024)$ & & $(0.031)$ \\
\hline Message about health and soy (dummy $=1$ & & -0.005 & & $0.086^{* *}$ \\
\hline for health \& soy, 0 otherwise) & & $(0.024)$ & & $(0.031)$ \\
\hline Message about environment and beef & & $-0.054^{*}$ & & $0.080^{* *}$ \\
\hline (dummy = 1 for envir. \& beef, 0 otherwise) & & $(0.024)$ & & $(0.031)$ \\
\hline Message about environment and soy & & $-0.050^{*}$ & & $0.106^{* *}$ \\
\hline (dummy = 1 for envir. \& soy, 0 otherwise) & & $(0.024)$ & & $(0.031)$ \\
\hline \multirow[t]{2}{*}{ Sex (1: man, 0 : woman $)^{\mathrm{a}}$} & $0.125^{* *}$ & $0.135^{* *}$ & $-0.253^{* *}$ & $-0.104^{* *}$ \\
\hline & $(0.032)$ & $(0.041)$ & $(0.035)$ & $(0.028)$ \\
\hline \multirow[t]{2}{*}{ Age $^{a}$} & $0.003^{* *}$ & $0.003^{* *}$ & & $-0.005^{* *}$ \\
\hline & $(0.001)$ & $(0.001)$ & & $(0.001)$ \\
\hline \multirow[t]{2}{*}{ Education (1: no certificate to 6: PhD) ${ }^{\mathrm{a}}$} & $0.075^{* *}$ & $0.076^{* *}$ & $0.029^{*}$ & $0.037^{* *}$ \\
\hline & $(0.013)$ & $(0.009)$ & $(0.012)$ & $(0.009)$ \\
\hline Monthly net income, from 1 for income & -0.013 & -0.020 & 0.017 & $0.082^{* *}$ \\
\hline$<€ 1000$ to 7 for income $>€ 6000^{a}$ & $(0.017)$ & $(0.019)$ & $(0.010)$ & $(0.008)$ \\
\hline \multirow[t]{2}{*}{ Stand. devi $\varepsilon$} & $0.186^{* *}$ & $0.185^{* *}$ & $0.219^{* *}$ & $0.241^{* *}$ \\
\hline & $(0.005)$ & $(0.005)$ & $(0.006)$ & $(0.008)$ \\
\hline \multirow[t]{2}{*}{ Stand. dev. $\mu$} & $0.291^{* *}$ & $0.291^{* *}$ & $0.368^{* *}$ & $0.536^{* *}$ \\
\hline & $(0.009)$ & $(0.010)$ & $(0.012)$ & $(0.018)$ \\
\hline Observations & $\mathrm{N}=595$ & $\mathrm{~N}=595$ & $\mathrm{~N}=595$ & $\mathrm{~N}=595$ \\
\hline Log likelihood & -7.459 & -4.212 & -96.882 & -164.621 \\
\hline
\end{tabular}

Note: **: significant at $1 \%$; *: significant at $5 \%$. Standard errors in parentheses.

${ }^{a}$ Question from the exit questionnaire.

Table 4 shows a limited impact of successive messages on WTP for beef. Only the 4th message (1st column) or the ones on the environment (2nd column) have a significant and negative impact on WTP for beef. The magnitude of these coefficients is very low if compared to the constant, suggesting relatively solid preferences for meat. The health messages have no impact on WTP for beef.

Results of Table 4 show a stronger effect of information for soy products than for beef, which is visible when the absolute values of coefficients related to a specific type of information are compared in the 3rd column versus the 1 st column or in the 4 th column versus the 2 nd column. For instance, the message about environment 
and soy has a stronger impact for soy, with a coefficient equal to 0.106 (4th column), than the one for beef, with a coefficient equal to 0.050 in absolute value (2nd column). The messages providing information about both environment and health related to soy have a significant impact on the WTP for a soy-based product, even if the coefficients of these dummy variables are also relatively low compared to the constant. In general, messages relative to environmental issues have a stronger and significant effect if compared to health related claims. A possible explanation is that health messages are widely known, while environmental issues are relatively novel, with a significant impact on WTP. The bottom of Table 4 shows that socioeconomic variables, such as age or sex, play a significant but minor role on the magnitude of WTP.

The weak impact of messages on WTP was also verified with some other specifications, not reported in Table 4, including the specification in which the four dummies for the order of information were interacted with the four dummies indicating the type of messages. As robustness check of econometric estimations of Table 4, we also ran regressions by replacing €2.1, the lower bound of the WTP related to absence of purchase with the multiple price-list, by $€ 0$, which leads to conclusions similar to the ones of Table 4 . Thus, econometric estimations show a weak influence of messages on WTP.

\subsection{The Chosen Baskets of 5 Products}

We now analyze the basket of 5 products chosen by participants after WTP's elicitation. Recall that participants chose a basket of 5 units at each round (see Appendix B). The quantity choices were made (1) without any posted price, (2) by assuming the same price for the two products, and (3) for an overall quantity that is fixed and equal to 5 units. Table 5 shows the variations of quantities and WTP.

Table 5: Comparison between variations of selected quantities of products and variations of WTP.

\begin{tabular}{|c|c|c|}
\hline Between the 1 st round and the 5 th round (119 participants) & Beef & Soy \\
\hline Absolute variation of quantities ${ }^{a}$ & -0.764 & +0.764 \\
\hline Relative variation of quantities ${ }^{a}$ & $-23.03 \%$ & $+45.55 \%$ \\
\hline Relative variation of WTP & $-1.55 \%$ & $+3.59 \%$ \\
\hline Between the 1st round and the $3^{d}$ round & Beef & Soy \\
\hline \multicolumn{3}{|l|}{$\begin{array}{l}\text { Health information revealed first for groups G1 \& G2 (62 } \\
\text { participants) }\end{array}$} \\
\hline Absolute variation of quantities ${ }^{a}$ & -0.451 & +0.451 \\
\hline Relative variation of quantities ${ }^{a}$ & $-12.96 \%$ & $+29.78 \%$ \\
\hline Relative variation of WTP & $+2.37 \%$ & $+2.16 \%$ \\
\hline \multicolumn{3}{|l|}{$\begin{array}{l}\text { Environmental information revealed first for groups G3 \& G4 (57 } \\
\text { participants) }\end{array}$} \\
\hline Absolute variation of quantities ${ }^{a}$ & -0.631 & +0.631 \\
\hline Relative variation of quantities ${ }^{a}$ & $-20.11 \%$ & $+33.96 \%$ \\
\hline Relative variation of WTP & $-3.85 \%$ & $+3.09 \%$ \\
\hline
\end{tabular}

Note: ${ }^{a}$ within the basket of 5 products (see Appendix B)

Table 5 shows that the explanatory messages lead to a significant change in the chosen quantity. For the variations between round \#1 and round \#5, the top of Table 5 underscores an average shift of 0.764 units from beef towards soy. However, the relative change in the chosen quantities is larger than the relative change in WTP. Between the first round and the fifth round, the relative variations for the chosen quantities of beef and soy are respectively equal to $-23.03 \%$ and $+45.55 \%$, versus $-1.55 \%$ and $+3.59 \%$ for the WTP of beef and soy, respectively.

Table 5 shows an interesting result, since this difference between WTPs' variations and quantities' variations generated by the provision of information was generally overlooked by previous papers (including the numerous articles presented by Lusk and Shogren 2007). There are two possible explanations of the larger impact on quantities than on WTP. The first explanation is that choosing quantities for a basket of products under different contexts of information is more natural and more immediate than determining WTP for one unit of product. Indeed, in supermarkets, consumers are directly choosing products quantities rather than directly formulating WTP with a multiple-price list. The second explanation is linked to the fact that consumers place a greater value on soy burgers when several units are purchased, but they are unwilling to pay more for one unit of soy compared to one unit of beef, when only one unit of product is offered for determining WTP.

The bottom of Table 5 compares the impact of health messages (received first by groups G1 and G2), and the impact of environmental messages (received first by groups G3 and G4). The previous result is confirmed, 
since, again, the relative variations for chosen quantities are higher than those for WTP. There are further interesting implications regarding the effect of health and environmental claims on consumers' perception of new products. In fact, we observe stronger variations coming from the messages linked to the environment, compared to the variations coming from the messages on health, indicating that environment matters for consumers. The weaker impact of the message on health compared to the one on environment may come from the relative complexity of the message on beef and health, underlining the risks of overconsumption along with some health benefits linked to meat.

Table 6 details the choices of beef in the basket of 5 units for the different groups of participants. The signs $\Delta$ show the significant impact of messages on the chosen quantities of beef. The different types of messages, in particular when there are presented at the beginning, namely before rounds \#2 and \#3, lead to a significant decrease of choices for beef. Some econometric estimations confirmed the results by showing that the rounds of information and the different types of information have a significant impact on the reduction of the chosen quantity of beef and the increase of the chosen quantity of soy.

Table 6: Average quantities of beef selected in the basket for the different subgroups and from rounds R.\#1 to R.\#5.

\begin{tabular}{|c|c|c|c|c|c|c|c|c|c|}
\hline & $\begin{array}{l}\text { Quanti. } \\
\text { R .\#1 }\end{array}$ & Info & $\begin{array}{l}\text { Quanti. } \\
\text { R. \#2 }\end{array}$ & Info & $\begin{array}{l}\text { Quanti. } \\
\text { R. \#3 }\end{array}$ & Info & $\begin{array}{l}\text { Quanti. } \\
\text { R. \#4 }\end{array}$ & Info & $\begin{array}{l}\text { Quanti. } \\
\text { R. \#5 }\end{array}$ \\
\hline Group & & Health & & Health & & Envir. & & Envir. & \\
\hline G1 & & Beef & & Soy & & Beef & & Soy & \\
\hline & 3.53 & $\Delta^{* *}$ & 3.20 & $\Delta^{*}$ & 3 & $\Delta^{*}$ & 2.60 & & 2.47 \\
\hline Group & & Health & & Health & & Envir. Soy & & Envir. & \\
\hline G2 & & Soy & & Beef & & & & Beef & \\
\hline & 3.44 & $\Delta^{* * *}$ & 3.03 & & 3.06 & $\Delta^{* *}$ & 2.91 & $\Delta^{* * *}$ & 2.66 \\
\hline Group & & Envir. & & Envir. & & Health & & Health & \\
\hline G3 & & Beef & & Soy & & Beef & & Soy & \\
\hline & 3.21 & $\Delta^{* *}$ & 2.79 & $\Delta^{*}$ & 2.62 & & 2.76 & & 2.69 \\
\hline Group & & Envir. Soy & & Envir. & & Health & & Health & \\
\hline G4 & & & & Beef & & Soy & & Beef & \\
\hline & 3.07 & $\Delta * * *$ & 2.61 & $\Delta * *$ & 2.39 & & 2.29 & & 2.39 \\
\hline
\end{tabular}

Notes: $\Delta^{*}$ denotes significant difference at $10 \%, \Delta^{* *}$ denotes significant difference at $5 \%$ and $\Delta^{* * *}$ denotes significant difference at $1 \%$ as tested by the Wilcoxon test for comparing paired samples of quantities chosen between two successive rounds with the revelation of a new message. The absence of any $\Delta$ means the absence of significant difference.

\subsection{Estimation of the Demand Variation and the Value of Information}

From both WTP and chosen quantities, we expand our analysis computing the variation in demand for beef coming from providing information. Since the market for soy burgers is still small, we do not account for any market adjustments related to plant-based products. As seen by Foster and Just (1989), the value of information is a welfare estimation related to the demand shift. The methodology we apply is an extension of the one developed by Marette, Roosen, and Blanchemanche (2008) and Lusk and Marette (2010), and it only takes into account the relative variation of WTP. Differently from previous works on estimating the value of information, we take into account two effects for calibrating the demand shifts: the relative variations of WTP and the relative variations of quantities. We consider the following simple demand for beef by a representative consumer $i$, namely

$$
q_{i}^{D}(p, I)=A[I d+(1-I+I z) \times p]^{\epsilon}
$$

where: $p$ is the price of beef; $\epsilon$ the direct-price elasticity; $A, d$ and $z$ are parameters; $I$ represents the level of information. If the consumer $i$ is not aware of messages/characteristics at the time of the purchase, then $I=$ 0 . Conversely, $I=1$ means that the consumer is aware of the characteristic(s) and this awareness affects his consumption choice. The inverse demand is given by:

$$
p\left(q_{i}, I\right)=\left(\left[q_{i} / A\right]^{1 /}-I d\right) /(1-I+I z)
$$

The demand function (2) can be calibrated with market variables, such that it represents the per capita average monthly demand of beef burger. As a proxy of the equilibrium price, we used the average market price $P_{R}$ 
observed in several supermarkets in Lombardy at the time of the experiment. More precisely, we use the average value of observed prices for a beef burger (as in Figure 1) using a sample of 20 prices collected at different points of sale. We estimate the average per capita monthly consumption of ground beef $E(q)$ using the values declared by participants in the exit questionnaire. ${ }^{5}$ Using $P_{R}$ we first calibrate the demand $q_{i}^{D}(p, I)$ under the assumption $I=0$, meaning when no additional messages, as the ones provided during the experiment, are revealed to consumers. This calibrated demand $q_{i}^{D}(p, I)$ represents the average monthly consumption per participant of ground beef $E(q)$. With $E(q), P_{R}$ and $\epsilon$ introduced in eq. (2) and with $I=0$, the parameter $A$ is calibrated for satisfying eq. (2) and is equal to $E(q)=A\left[P_{R}\right]^{\epsilon}$.

The parameters $d$ and $z$ are estimated with the variations in WTP and chosen quantities estimated in the lab. We restrict our estimation to a Marshallian approximation of demand variations. ${ }^{6}$ First, let us consider values WTP $i 1$ and WTP $i 2$ indicating participant $i^{\prime}$ s WTP before and after the complete revelation of information, namely after round \#5. The relative variation in average WTP provides a first measure of the inverse demand shift, $\omega=[E(\mathrm{WTP} 2)-E(\mathrm{WTP} 1)] / E(\mathrm{WTP} 1)$, where $E($.$) denotes the overall expected value considering all$ participants. The WTP represents the maximum amount of money that a consumer is ready to pay for one unit of product, which means that from eq. (3), WTP gives information about $p\left(1, I_{i}\right)$, namely when one unit is purchased (i. e. $q_{i}=1$ ). The relative variation of WTP coming from the revelation of information in the lab gives an estimation of the relative variation of the price $p\left(1, I_{i}\right)$ related to the information. In eq. (4) introduced below, the price under the absence of information is equal to $p(1,0)$, and the price with complete information is equal to $p(1,1)$, with $p\left(q_{i}, I_{i}\right)$ given by (3).

The relative variation in average chosen quantities is $\delta=[E(X 2)-E(X 1)] / E(X 1)$, where values $X_{1}^{i}$ and $X_{2}^{i}$ indicates participants $i$ 's quantity choice of a product before and after the complete revelation of information. We assume that, when making quantity choices, consumers perceive the average price $P_{R}$ as the market and equilibrium price of beef (see Appendix B). This relative shift in quantities represents the possible demand shift given by (4) at the equilibrium price $P_{R}$. From eq. (2), the purchased quantity at the price $P_{R}$ and under the absence of information is equal to $q_{i}^{D}\left(P_{R}, 0\right)$, and the purchased quantity with information is equal to $q_{i}^{D}\left(P_{R}, 1\right)$. The values $d$ and $z$ are given by solving the following system of eq. (4), accounting for both the relative variations of prices and quantities due to the revelation of messages:

$$
\left\{\begin{array}{l}
\frac{p(1,1)-p(1,0)}{p(1,0)}=\omega \\
\frac{q_{i}^{D}\left(P_{R}, 1\right)-q_{i}^{D}\left(P_{R}, 0\right)}{q_{i}^{D}\left(P_{R}, 0\right)}=\delta
\end{array}\right.
$$

Figure 3 shows the demand shift related to equations of the system (4) when information about beef and soy is revealed. Following the standard convention, price is measured on the vertical axis and quantity on the horizontal axis. The equilibrium price is represented by $P_{R}$. The initial demand is represented by the line $p\left(q_{i}, 0\right)$. For $I=0$, the purchased quantity by a consumer $i$ is $q_{i}^{D}\left(P_{R}, 0\right)=E(q)$, where $E(q)$ is the average monthly consumption of ground beef used for the calibration. The information leads to a decline of the demand from $p\left(q_{i}, 0\right)$ to $p\left(q_{i}, 1\right)$. This demand shift is calibrated with eq. (4) and is detailed in Figure 3 where parameters $\omega$ and $\delta$ are represented.

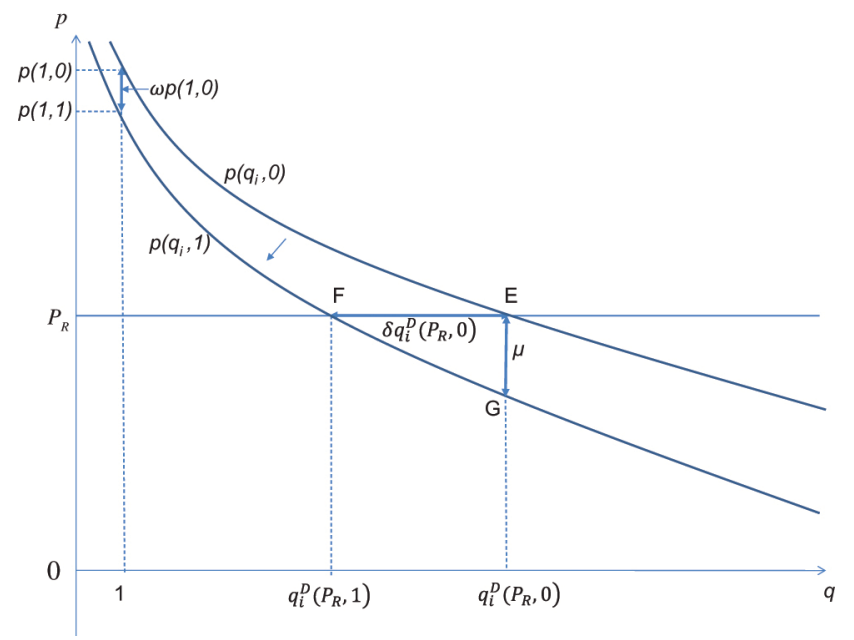

Figure 3: Beef demand shift and the value of information. 
From Figure 3, we are interested on estimating these two values: (a) the price premium $\mu$ at the equilibrium point, where $\mu$ most likely differs from the WTP variation for a unit quantity; (b) the value of information, given by the area $F E G$, that represents the welfare gain from being informed and shifting consumption from $q_{i}^{D}\left(P_{R}, 0\right)$ to $q_{i}^{D}\left(P_{R}, 1\right)$ (Foster and Just 1989).

Table 7 presents the data we use for the estimation and the results. More precisely, the top of Table 7 provides the market parameters and some results coming from the lab experiment. The relative variations $\omega$ and $\delta$ indicated in Figure 3 and in eq. (4) come from the revelation of all messages in the lab, namely between stage $\# 1$ and stage \#5, as indicated at the top of Table 5.

Table 7: Parameters for calibrating the welfare variation in Italy.

\begin{tabular}{|c|c|c|}
\hline Description & Variable & Value \\
\hline \multicolumn{3}{|l|}{$\begin{array}{l}\text { PARAMETERSFrom } \\
\text { time series and } \\
\text { observed data }\end{array}$} \\
\hline $\begin{array}{l}\text { Price of one steak of } \\
\text { ground beef } \\
(€ / 100 \mathrm{~g})^{\mathrm{a}}\end{array}$ & $P_{R}$ & $€ 1.3$ \\
\hline $\begin{array}{l}\text { Own-price elasticity } \\
\text { of demand }{ }^{b} \\
\text { From the lab } \\
\text { experiment }\end{array}$ & $\hat{\epsilon}$ & -1.1 \\
\hline $\begin{array}{l}\text { Number of steak of } \\
\text { beef consumed over } \\
\text { one month }\end{array}$ & $E(q)$ & 6.32 \\
\hline $\begin{array}{l}\text { Relative variation in } \\
\text { the average WTP }\end{array}$ & $\omega$ & -0.015 \\
\hline $\begin{array}{l}\text { Relative changes in } \\
\text { chosen quantity } \\
\text { RESULTS }\end{array}$ & $\delta$ & -0.230 \\
\hline $\begin{array}{l}\text { Price premium at } \\
\text { point E in Figure } 3 \\
(€)^{c}(\text { Price } \\
\text { premium }) /(\text { market } \\
\text { price })^{c}\end{array}$ & $\mu \mu / P_{R}$ & $€-0.364-0.280$ \\
\hline $\begin{array}{l}\text { Value of Information } \\
\text { for } 1 \text { month (area } \\
\text { Figure } 3)(€)^{c}\end{array}$ & FEG & $€ 0.287$ \\
\hline $\begin{array}{l}\text { (Value of } \\
\text { Information) } /(\text { initial } \\
\text { expenditure }(\%)^{c}\end{array}$ & $F E G /\left(P_{R^{*}} E(q)\right)$ & $3.49 \%$ \\
\hline
\end{tabular}

Note: ${ }^{\text {T}}$ The average price of the pack shown on Figure 1 was $€ 2.6$ for two steaks (see Figure 1 ). We consider one steak, corresponding to a reasonable quantity for participants who declare the frequency of consumption tin the questionnaire.

b Authors' estimation for Italy.

'Authors' estimation with the Mathematica ${ }^{\circledR}$ program presented in Appendix C.

Results are presented in the bottom panel of Table 7. These results related to Figure 3 are computed with a Mathematica ${ }^{\circledR}$ program given in Appendix $C$. The negative premium for beef at the initial equilibrium point of the demand function is quite significant with $\mu / P_{R}$ equal to -0.280 ; this value is much higher than the relative variation of the WTP for one unit of product $(\omega=-0.015)$ as presented in Figure 3. The value of information is relatively low, since it represents $3.49 \%$ of the initial expenditure for beef, computed as the product of price and purchased quantity. Moreover, as also suggested by Figure 3, the value of information strongly depends on the shape of the demand function. The value of information (FEG) can eventually be generalized and extrapolated to the whole Italian population. Knowing the value of information for the whole Italian population can be helpful to carry out a cost-benefit analysis comparing it to the cost of revealing information.

Even if the value of information equal to $€ 0.287$ in Table 7 is relatively low, it is still higher than the alternative value that could be computed by omitting the relative changes in the chosen quantity $\delta$, as presented in (3). Omitting $\delta$, once the parameter $z=0$ in eqs. (2) and (3), and with only the first line of eq. (4), the estimated value of information would be 11 times lower. In other words, abstracting from the relative changes in the chosen quantity $\delta$ would lead to a significant underestimation of the value of information, with consequences for cost-benefit analyses. 


\subsection{The Impact of a Beef without GMO Feeding}

We now turn to the study of the WTP and the basket of 5 products chosen by participants, after the introduction of beef labelled as "Fed without GMO" at round \#6. Table 8 shows how this label sways the WTP and the chosen quantities.

Table 8: Relative variations of WTP and selected quantities.

\begin{tabular}{lll}
\hline Between the 1th round and the 6th round & Beef & Soy \\
\hline Relative variation of WTP & $+0.74 \%$ & $+3.79 \%^{* *}$ \\
Relative variation of quantities a & $-22.02 \%^{* *}$ & $+22.02 \%^{* *}$ \\
Between the 5 th round and the 6th round & $+2.33 \% \%^{* *}$ & $+0.19 \%$ \\
Relative variation of WTP & $+1.38 \%$ & $-1.38 \%$ \\
\hline Relative variation of quantities ${ }^{\text {a }}$ & & \\
\hline
\end{tabular}

Note: ${ }^{a}$ within the basket of 5 products, ${ }^{* *}$ denotes significant difference at $1 \%$ as tested by the Wilcoxon test for comparing paired sample of WTP or quantities.

The top of Table 8 shows the complete effect of all messages, including the last one on GMOs. The bottom of Table 8 underlines the weak impact of this last message on participants' preferences between the 5th and the 6th round: only the increase of WTP for beef is statistically significant, but this increase is relatively small. For the WTP of beef, the increase of $2.33 \%$ offsets the small decrease of $1.55 \%$ observed between the 1 st round and the 5 th round, as shown at the top of Table 5. For other variables at the bottom of Table 8 , variations between the 5 th round and the 6th round are not statistically significant as tested by the Wilcoxon test for comparing paired samples. Providing a label "Fed without GMO" does not drastically "alter" quantity choices towards more beef compared to soy. In other words, there is no major reversal of preference from meat to plant substitutes linked only to better feeding of animals and, the significant quantity effects we observe in the top panel (soy $+22.02 \%$, beef $-22.02 \%$ ) are mainly due to the effect of information provided during rounds \#2-\#5.

\section{Conclusion}

The explanatory messages on meat and plant-based substitute have a relatively significant impact on chosen quantities of products and a very small one on WTP. This underscores an interest for soy burger meat that cannot however replace the habit to eat meat. This paper underlines a relatively strong attitude towards beef that hinders a shift towards a plant-based diet in Milan and in Lombardy.

One important result of this paper is the larger impact of information on chosen quantities compared to the limited impact on WTP. ${ }^{7}$ One possible explanation for this result is that making quantity choices for a basket of products under different contexts of information may be more natural and more immediate than determining WTP for one unit of product. Indeed, in supermarkets, consumers are directly choosing quantities rather than formulating WTP for one unit. Another explanation is linked to the fact that consumers place a greater value on soy burgers when several units are purchased, but they are unwilling to pay more for soy than for beef, when only one unit is offered for determining WTP. Future experiments could try to understand the drivers of this result by varying the number of units offered with an auction procedure and with the chosen basket, or alternatively, by asking participants about their perceptions.

Another possible extension would consist to study the optimal regulation for satisfying consumers. The significant impact of information on choices raises some questions about the opportunity of regulation. Providing generic explanations and recommendations on the impact of beef production and consumption could be useful for developing consumers' knowledge and sensitivity, but this is not the panacea for changing behaviors. While the lab allows a tight control of revealed information and consumers' attention to this revealed information, the main shortcoming of informative campaigns in a real context lies in the imperfect recall of consumers and the possible confusion when information is technical or complex. The low impact coming from providing generic information in a real setting may lead environmentalists, nutritionists and/or politicians in charge of regulation to turn to alternative fiscal instruments like a per-unit tax on beef or a per-unit subsidy on soy. Despite limitations coming from our experiment, evidence-based policies about meat sustainability should take into account the limited impact of information on WTP of meat and plant-based alternatives, and consider possible persistent behaviors of Italian consumers. 


\section{Acknowledgements}

We thank Lavinia Gaia Bulla and Federica Faggioli for their precious assistance in the lab in Milan. The authors only are responsible for any omissions or deficiencies.

\section{Funding}

The research leading to these results received funding from the European Union's H2020 Program under Grant Agreement number 633692 (SUSFANS: Sustainable food and nutrition security through evidence based EU agro-food policy, details on http://www.susfans.org/).

\section{Notes}

1 Even if hypothetical WTP is likely to be upward biased, recent contributions seem to downplay risks of biases for private goods. By comparing hypothetical and non-hypothetical responses, Lusk and Schroeder (2004) showed that marginal WTP for a change in quality/characteristic is, in general, not statistically different across hypothetical and real payment settings.

2 Field experiments show that imperfect recall, lack of time before purchasing, the great number of purchased products or/and confusion about complex information characterize many consumers in the supermarket.

3 This paper only considers WTP with the highest "yes" for the 119 participants. Among them, 29 participants were also characterized by lower limit, LL, with LL < WTP and for which the reply was "maybe" or "no" for prices lower than LL. Marette, Blanchemanche, and Roosen (2013) underscore multiplicity of market equilibria coming from LL.

4 In the initial explanations at round\#1, we carefully explained that six combinations were possible, namely $\{(0 \mathrm{~B}, 5 \mathrm{~S}),(1 \mathrm{~B}, 4 \mathrm{~S}),(2 \mathrm{~B}, 3 \mathrm{~S})$, (3 B, 2 S), (4 B, 1 S), (5 B, 0 S)\}, with notations $B$ for beef and $S$ for Soy.

5 The question was "How many times do you eat ground beef?" with 8 possible replies regarding the frequency and going from "Twice a day" to "never". From this reply, we estimated the number of steaks of beef consumed over one month.

6 Rousu et al. (2014) directly use the Hicksian definition of the WTP with method combining market data and WTP variations coming from lab experiments.

7 In particular, it means that the extent of demand shifts differs with the quantity purchased by consumers/participants as shown on Figure 3.

\section{References}

Alphonce, R., and F. Alfnes. 2017. "Eliciting Consumer WTP for Food Characteristics in a Developing Context: Application of Four Valuation Methods in an African Market." Journal of Agricultural Economics 68: 123-14

Andersen, S., G. Harrison, M. Lau, and E. Rutström. 2006. “Elicitation Using Multiple Price List Formats.” Experimental Economics 9: 383-405 de Boer, ]., C. T. Hoogland, and ]. J. Boersema. 2007. "Towards More Sustainable Food Choices: Value Priorities and Motivational Orientations." Food Quality and Preference 18 (7): 985-996.

Foster, W., and R. Just. 1989. "Measuring Welfare Effects of Product Contamination with Consumer Uncertainty." Journal of Environmental Economics and Management 17: 266-283

González, A.D., B. Frostell, and A. Carlsson-Kanyama. 2011. “Protein Efficiency per Unit Energy and per Unit Greenhouse Gas Emissions: Potential Contribution of Diet Choices to Climate Change Mitigation." Food Policy 36: 562-570

Graça, J., M.M. Calheiros, and A. Oliveira. 2015. "Attached to Meat? (Un)Willingness and Intentions to Adopt a More Plant-Based Diet." Appetite 95: 113-125

Grunert, K. 1997. “What's in A Steak? A Cross-Cultural Study on the Quality Perception of Beef.” Food Quality and Preference 8: 157-174

Hoek, A. C., P. A. Luning, A. Stafleu, and C. de Graaf. 2004. "Food-Related Lifestyle and Health Attitudes of Dutch Vegetarians, NonVegetarian Consumers of Meat Substitutes, and Meat Consumers." Appetite 42 (3): 265-272.

Krystallis, A., K. G. Grunert, M. D. de Barcellos, T. Perrea, and W. Verbeke. 2012. “Consumer Attitudes Towards Sustainability Aspects of Food Production: Insights from Three Continents." Journal of Marketing Management 28 (3-4): 334-372.

Lock, K., R. D. Smith, A. D Dangour, M. Keogh-Brown, G. Pigatto, C. Hawkes, R. M. Fisberg, and Z. Chalabi. 2010. “Health, Agricultural, and Economic Effects of Adoption of Healthy Diet Recommendations." The Lancet 376 (9753): 1699-1709.

Lusk, J.L., and S. Marette. 2010. “Welfare Effects of Food Labels and Bans with Alternative Willingness to Pay Measures." Applied Economic Perspectives \& Policy 32 (2): 319-337.

Lusk, J. L., and T.C. Schroeder. 2004. “Are Choice Experiments Incentive Compatible: A Test with Quality Differentiated Beef Steaks.” American Journal of Agricultural Economics 86 (2): 467-482.

Lusk, J. L., and ]. F. Shogren. 2007. Experimental Auctions. Methods and Applications in Economic and Marketing Research. Cambridge, UK: Cambridge University Press.

Marette, S., S. Blanchemanche, and ]. Roosen. 2013. “Multiple Equilibria with a Multiple Price List.” Applied Economics Letters 20 (8): $809-812$.

Marette, S., J. Roosen, and S. Blanchemanche. 2008. "Taxes and Subsidies to Change Eating Habits When Information Is Not Enough: An Application to Fish Consumption." Journal of Regulatory Economics 34: 119-143

Masters, W. A., and D. Sanogo. 2002. "Welfare Gains from Quality Certification of Infant Foods: Results from a Market Experiment in Mali." American Journal of Agricultural Economics 84: 974-989 
Roosen, J., and S. Marette. 2011. “Making the 'Right' Choice Based on Experiments: Regulatory Decisions for Food and Health." European Review of Agricultural Economics 38 (3): 361-381.

Rousu, M. C., S. Marette, J. F. Thrasher, and ]. L. Lusk. 2014. “The Economic Value to Smokers of Craphic Warning Labels on Cigarettes: Evidence from Combining Market and Experimental Auction Data." Journal of Economic Behavior \& Organization 108: 123-134

Sarrias, M. 2016. "Discrete Choice Models with Random Parameters in R: The Rchoice Package." Journal of Statistical Software 74 (10): 1-30.

Wansink, B., S. Sonka, and C. Hasler. 2004. “Front-Label Health Claims: When Less Is More.” Food Policy 29: 659-667

Wein, H. 2012. "Risk in Red Meat?" NIH Research Matters. Washington D.C.: National Institute of Health. March 26, 2012.

Westhoek, H., J.P. Lesschen, T. Rood, S. Wagner, A. De Marco, D. Murphy-Bokern, A. Leip, et al. 2014. "Food Choices, Health and Environment: Effects of Cutting Europe's Meat and Dairy Intake." Global Environmental Change 26: 196-205

Zur, I., and A. Klöckner. 2014. “Individual Motivations for Limiting Meat Consumption.” British Food Journal 116 (4): 629-642.

\section{Appendix}

\section{A The Multiple-price List for Each Product}

For each product and each round, a multiple-price list was presented on a new paper sheet. After a brief presentation of the product (weight, content of fat) and one picture of the product (given in Figure 1), the multiple-price list for one product was as presented as following:

[Picture of the product]

Would you purchase the product at the following prices?

For each line check off either yes, no or maybe. Please check off only one option for each price.

\begin{tabular}{|c|c|c|c|}
\hline & YES & NO & Maybe \\
\hline$€ 2.20$ & $\square$ & $\square$ & $\square$ \\
\hline$€ 2.30$ & $\square$ & $\square$ & $\square$ \\
\hline$€ 2.40$ & $\square$ & $\square$ & $\square$ \\
\hline$€ 2.50$ & $\square$ & $\square$ & $\square$ \\
\hline$€ 2.60$ & $\square$ & $\square$ & $\square$ \\
\hline$€ 2.70$ & $\square$ & $\square$ & $\square$ \\
\hline$€ 2.80$ & $\square$ & $\square$ & $\square$ \\
\hline$€ 2.90$ & $\square$ & $\square$ & $\square$ \\
\hline$€ 3$ & $\square$ & $\square$ & $\square$ \\
\hline$€ 3.10$ & $\square$ & $\square$ & $\square$ \\
\hline$€ 3.20$ & $\square$ & $\square$ & $\square$ \\
\hline$€ 3.30$ & $\square$ & $\square$ & $\square$ \\
\hline$€ 3.40$ & $\square$ & $\square$ & $\square$ \\
\hline$€ 3.50$ & $\square$ & $\square$ & $\square$ \\
\hline$€ 3.60$ & $\square$ & $\square$ & $\square$ \\
\hline$€ 3.70$ & $\square$ & $\square$ & $\square$ \\
\hline$€ 3.80$ & $\square$ & $\square$ & $\square$ \\
\hline
\end{tabular}

\section{B Quantity choice with the basket of 5 products}

At the end of each round, each participant indicated their quantity choice on a new paper sheet. The paper sheet was organized as following:

If the 2 products were sold at the same price and if you should buy 5 products, how many products would you buy?

You are free to choose any combination leading to a total of 5 products.

In the right column, indicate the number of products you would choose: 


\section{Computation for Table 7 made with the Mathematica ${ }^{\circledR}$ Software}

\section{The Program:}

( ${ }^{*}$ Table 7-Parameters *)

$\mathrm{pb}=1.3$;

$\mathrm{e}=-1.1$;

$\mathrm{qT}=6.32 ;$

del $=-0.015$;

gam $=-0.23$;

( Calibration \& Computation of demand ${ }^{*}$ )

$\mathrm{A}=\mathrm{qT} /\left(\mathrm{pb}^{\wedge} \mathrm{e}\right)$;

inter $=\left(\left(((1) /(\mathrm{A}))^{\wedge}(1 / \mathrm{e})\right)-\mathrm{d}\right) / \mathrm{z}$;

dddd $=\left((1 / \mathrm{A})^{\wedge}(1 / \mathrm{e})\right)$;

val = inter $/$ dddd;

$\mathrm{fnfn}=\left((\mathrm{A})^{*}\left(\left(\mathrm{~d}+\mathrm{z}^{*} \mathrm{pb}\right)^{\wedge} \mathrm{e}\right)\right)$;

marche $=\left(\mathrm{A}^{*}((\mathrm{pb}) \wedge \mathrm{e})\right)$;

claSS $=\mathrm{fnfn} /$ marche;

RESULTS

resu2 $=$ Simplify $\left[\{d, z\} / . N S o l v e\left[\left\{\right.\right.\right.$ inter $\left.\left.\left.==\operatorname{dddd}^{*}(\operatorname{del}+1),\left(\operatorname{marche}^{*}(\operatorname{gam}+1) / A\right)^{\wedge}(1 / e)==\left(\left(d+z^{*} p b\right)\right)\right\},\{d, z\}\right]\right]$; val2 $=(\mathrm{qT} / \mathrm{A})^{\wedge}(1 / \mathrm{e})$

val1 $=\left(\left(((\mathrm{qT}) /(\mathrm{A}))^{\wedge}(1 / \mathrm{e})\right)-\operatorname{resu2}[[1,1]]\right) / \operatorname{resu2}[[1,2]]$;

dddddddd = val1-val2

ssssd $=$ dddddddd $/$ val2

VALUE of INFORMATION

$\mathrm{fnfn}=\left((\mathrm{A})^{*}\left(\left(\operatorname{resu} 2[[1,1]]+\operatorname{resu} 2[[1,2]]^{*} \mathrm{pb}\right)^{\wedge} \mathrm{e}\right)\right)$;

$\left.\mathrm{vv}=\left(((\mathrm{q}) /(\mathrm{A}))^{\wedge}(1 / \mathrm{e})\right)-\operatorname{resu2}[[1,1]]\right) / \operatorname{resu2}[[1,2]]$;

$\mathrm{fff}=$ Integrate $[\mathrm{vv},\{\mathrm{q}, \mathrm{fnfn}, \mathrm{qT}\}]$;

zze $=(q T-f n f n)^{*} p b ;$

Valu $=$ zze-fff

ssssddddd $=$ Valu $/\left(\mathrm{qT}^{*} \mathrm{pb}\right)$

\section{The Results:}

\section{RESULTS}

$-0.364753$

$-0.280579$

VALUE of INFORMATION

0.287103

0.0349443 